Authors have nothing to disclose with regard to commercial support.

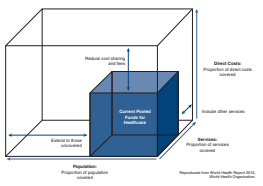

\section{CARDIOTHORACIC SURGERY IN THE ERA OF UNIVERSAL HEALTH COVERAGE \\ To the Editor:}

Mennander and colleagues ${ }^{1}$ nicely account the success of the Nordic Countries in providing free, high-quality, and sustainable cardiac surgical services through investment in specialist training for cardiothoracic surgery (CTS). While humble in their comments regarding costs, the authors nod to a crucial point regarding the success of these health systems, which deserves some elevation: "health care including [cardiothoracic] surgery is free for citizens. A small nominal fee (USD 10-20 per visit) may apply to outpatient and hospital care." 1

The United States bills high costs for CTS, ranging from an average of more than $\$ 40,000$ for mitral valve repairs to more than $\$ 100,000$ for Norwood procedures. ${ }^{2,3}$ Additional patient expenses are incurred with consequent costs for medication, follow-up, and postoperative rehabilitation. In total, $91.5 \%$ of the US population is either covered through private insurance or are eligible for Medicaid, Medicare, or Veterans Affairs Health Care; however, 8.5\% (27.5 million people) of the population do not have health insurance or lack any sustainable means to obtain long-term access to coverage. ${ }^{4}$ Consequently, it becomes highly likely that if any of these patients require CTS of any sort, cost would be prohibitive. Market-based health systems have led to the creation of significant disparities in the United States: on one city block, a hospital performs robotic surgery with a million-dollar robot; on another city block, a patient is dying from treatable chronic disease because of lack of health insurance. Universal health coverage (UHC) comes in different forms and shapes, but all show the same success: near-absence of financial hardship and high quality of care.

Although financial hardship due to CTS has been understudied in the United States, it is known that relatively less costly interventions such as trauma care

\footnotetext{
The Editor welcomes submissions for possible publication in the Letters to the Editor section that consist of commentary on an article published in the Journal or other relevant issues. Authors should: • Include no more than 500 words of text, three authors, and five references. • Type with double-spacing. • See http://jtcs.ctsnetjournals.org/ misc/ifora.shtml for detailed submission instructions. • Submit the letter electronically via jtcvs.editorialmanager.com. Letters commenting on an article published in the JTCVS will be considered if they are received within 6 weeks of the time the article was published. Authors of the article being commented on will be given an opportunity of offer a timely response ( 2 weeks) to the letter. Authors of letters will be notified that the letter has been received. Unpublished letters cannot be returned.
}

put more than $70 \%$ of uninsured patients at risk for catastrophic health expenditure 5 -therefore, it can be inferred that CTS, with its notably greater procedural costs, might have a much more significant, deleterious impact. The establishment of financial safety net mechanisms as seen in single-payer models not only ensures that more patients are able to benefit from CTS when needed but also minimizes postoperative financial difficulties and may mitigate disparities due to baseline socioeconomic status.

On September 23, 2019, the high-level meeting on UHC will take place at the United Nations General Assembly, where state leaders will adopt the Political Declaration on UHC. The Declaration, unfortunately, lacks strong commitment to accelerate political and economic efforts to move toward UHC by the United Nation's 2030 goal, and many civil society voices, including professional societies, have been left unheard or omitted from this discourse. Our cardiac surgical societies are not sitting at the decision-making table and therefore, allowances are not being made to expand access to critical services in our field. As a result, cardiac care will remain under-recognized as an indispensable component of UHC, broadening the gap of disparities and access to vulnerable populations. As practitioners, researchers, and promoters of optimal health in our patients and communities, are we not inclined to be advocates for universal health coverage, too?

\section{Dominique Vervoort, $M D^{a, b}$ JaBaris D. Swain, $M D, M P H^{c}$ \\ ${ }^{a}$ Johns Hopkins Bloomberg School of Public Health Baltimore, $M d$ \\ ${ }^{b}$ Johns Hopkins Carey Business School \\ Baltimore, $M d$ \\ ${ }^{c}$ Division of Cardiovascular Surgery Hospital of the University of Pennsylvania Philadelphia, $\mathrm{Pa}$}

\section{References}

1. Mennander A, Gudbjartsson T, Jeppsson A, Hjortdal V, Tønnessen T. Specialis training for cardiothoracic surgery in the Nordic countries. J Thorac Cardiovasc Surg. 2020;159:1002-8.

2. Vassileva CM, Shabosky J, Boley T, Markwell S, Hazelrigg S. Cost analysis of isolated mitral valve surgery in the United States. Ann Thorac Surg. 2012;94: 1429-36.

3. Pasquali SK, Jacobs ML, He X, Shah SS, Peterson ED, Hall M, et al. Variation in congenital heart surgery costs across hospitals. Pediatrics. 2014;133: e553-60.

4. United States Census Bureau. Income, Poverty and Health Insurance Coverage in the United States. 2018. Available at: https://www.census.gov/ newsroom/press-releases/2019/income-poverty.html. Accessed September 10, 2019.

5. Scott JW, Raykar NP, Rose JA, Tsai TC, Zogg CK, Haider AH, et al. Cured into destitution: catastrophic health expenditure risk among uninsured trauma patients in the United States. Ann Surg. 2018;267:1093-9.

https://doi.org/10.1016/j.jtcvs.2019.09.160 